\title{
Didactics of ICT in Secondary Education: Conceptual Issues and Practical Perspectives
}

\author{
Said Hadjerrouit \\ University of Agder, Kristiansand, Norway
}

Said.Hadjerrouit@uia.no

\begin{abstract}
While there is a huge research literature on the field of ICT (Information and Communication Technology) as a tool in teaching and learning, there is much less research on the area of ICT as a subject or similar designations such as school informatics. As a result, there is a lack of theoretical grounding of the didactics of ICT and associated teaching and learning processes. One of the main reasons for the lack of theoretical underpinnings of the didactics of ICT is that there have been in the past and there persist even now strong disagreements and confusion about the nature of ICT as a school subject. While the content of the subject has been clearly defined in the school curriculum, the didactics of ICT is still unclear. This paper suggests ways forward in formulating a framework for conceptualizing the didactics of ICT. The framework draws on research in learning paradigms, epistemology, general didactics, conceptual, and curricular issues of ICT. The article also reports on implementations and evaluations of the framework that were carried out by trainee teachers in secondary schools.
\end{abstract}

Key words: Conceptual framework, design-based research, didactics of ICT, learning theory, school informatics, trainee teacher.

\section{Introduction}

The ICT subject curriculum from 2006 is intended to improve the content of the subject, on the one hand, and to enhance the teaching and learning of ICT, on the other hand. Unfortunately, the curriculum is restricted to what is to be taught (content) and makes few suggestions as to what didactical skills teachers need to acquire in order to teach ICT as a school subject. Hence, despite a clear specification of content, ICT lacks a disciplined approach to didactics. The lack of a coherent framework for the didactics of ICT makes it difficult to identify which didactical skills teachers need to acquire in secondary schools, which learning strategies are efficient to construct knowledge, and which assessment approaches are adequate to assess the students' learning.

This paper argues for a framework for conceptualizing the didactics of ICT with the aim of contributing to a better understanding of teaching and learning processes that take place in secondary

Material published as part of this publication, either on-line or in print, is copyrighted by the Informing Science Institute. Permission to make digital or paper copy of part or all of these works for personal or classroom use is granted without fee provided that the copies are not made or distributed for profit or commercial advantage AND that copies 1) bear this notice in full and 2) give the full citation on the first page. It is permissible to abstract these works so long as cred it is given. To copy in all other cases or to republish or to post on a server or to redistribute to lists requires specific permission and payment of a fee. Contact Publisher@InformingScience.org to request redistribution permission. school classrooms. The main research objective of this work is to investigate the effectiveness of the framework and the factors influencing its implementation in secondary schools. Among many research approaches to ICT education, design-based research is one of the most appropriate methodologies for designing, implementing, and evaluating the framework through successive cycles of 
experimentations (Barab \& Squire, 2004; Bell, 2004; The Design-Based Research Collective 2003).

The remainder of this article is structured as follows. First, the design-based research paradigm and associated research questions are described. Then, the current state of the didactics of ICT is presented. This is followed by the design of a framework for the didactics of ICT. The evaluation and discussion of the framework are then presented, followed by the evolution of the framework. Finally, some conclusions on further work conclude the article.

\section{Research Methodology: Design-Based Research}

This work is situated within teacher education. It is aimed at analyzing the deficiencies of teaching and learning ICT, designing a solution based on a conceptual framework, implementing and evaluating the framework in secondary schools. The work involves trainee teachers, school teachers, and school students, as well as a number of influencing factors. Given the complexity of these settings, design-based research is one of the most appropriate paradigms to investigate teaching and learning processes in the field of ICT in secondary schools.

Design-based research embodies specific theoretical frameworks about teaching and learning, and helps to understand how the frameworks tend to be continuously developed and refined through an iterative process. The essential characteristic of design-based research is that it describes a continuous cycle, or feedback loop, of gradual refinement of teaching and learning processes based on a theoretical framework. Each cycle has four major phases: analysis, design, implementation, and evaluation. These phases are interdependent and reciprocal. Refinements of educational practice are continually made through successive cycles of experimentations, where the shortcomings of each cycle are identified, re-designed, re-implemented, and re-evaluated. Likewise, when applied to the field of ICT, design-based research involves the following four steps (Figure 1):

1. It begins with the analys is of the problems and deficiencies of current educational practice in the field of ICT. A critical literature review is conducted, thereby generating the formulation of research questions.

2. It continues with the design of a framework for the didactics of ICT, which will be used to overcome the deficiencies of current practice. The framework supports the designers' work, forming the foundation for implementation and evaluation.

3. Then, an attempt at implementing the suggested framework is performed, using multiple methods for collecting empirical data, e.g. formal and informal discussions, project report analys is, observations, field notes, etc.

4. Finally, the implementation of the framework is evaluated. The evaluation is concerned with the systematic analys is of the data collected and critical reflection according to the features of the framework and the research questions. 


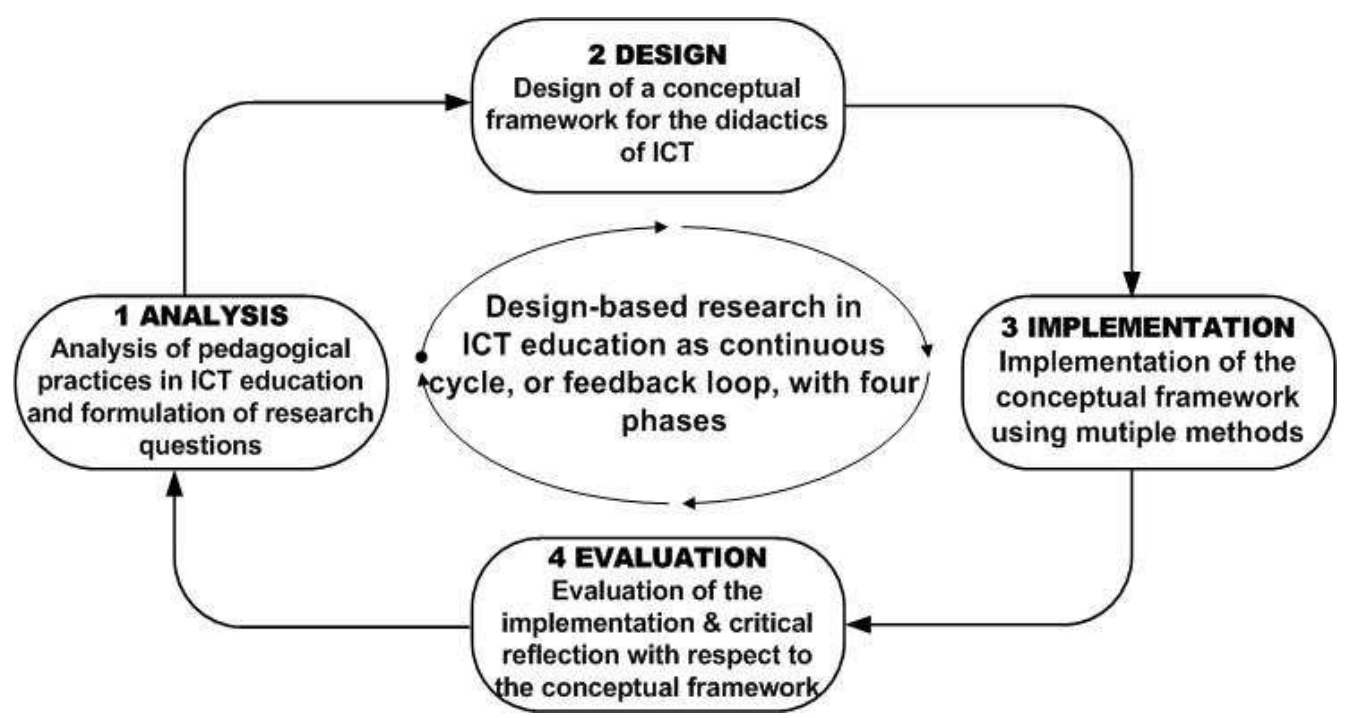

Figure 1: Design-based research in ICT education

\section{Research Questions}

The research purpose of the work is threefold: (a) to analyse trainee teachers' uses of the framework for the didactics of ICT; (b) to explore personal and contextual factors that affect the implementation of the framework; (c) to identify the implications of the framework for the teaching and learning of ICT in secondary schools. Consequently, the work focuses on the following research questions:

1. How do trainee teachers use the framework in the ir teaching of ICT in secondary schools?

2. How do trainee teachers' personal perceptions of ICT affect the use of the framework in secondary schools?

3. What are the contextual factors that emerge as influential on trainee teachers' uses of the framework?

4. What are the implications of the framework for the teaching and learning of ICT in secondary schools?

\section{Current State of ICT Didactics}

According to the research literature (Rautopuro et al., 2006; Webb, 2002), there are three separate aspects of information and communication technology (ICT) in school education:

a) Using ICT as a tool to support teaching and learning processes, for example using a word processor, spreadsheet or database in other subject areas such as mathematics or science.

b) Learning through ICT where the ICT facility becomes the whole learning environment by providing learning materials, such as LMS or Web-based learning.

c) Learning ICT as a subject, that is to say learning the know ledge, concepts, skills, and processes of ICT.

Using ICT as a tool and learning through ICT offer very little opportunity for students to learn the know ledge, concepts, and skills needed to master ICT as a subject. Learning ICT is more than the ability to operate and use a computer system. Hence, the acquisition of technical skills is only 
part of the problems encountered in teaching and learning ICT as a subject. Indeed, ICT education includes a sophisticated set of higher-order skills and cognitive abilities, such as analysing, designing, implementing, collecting and retrieving, organizing and managing, interpreting and representing, evaluating and creating information (Drenoyianni, 2004).

While there is a huge literature on the didactics of ICT as a tool and learning environment (learning through ICT), there is much less research on the teaching of ICT as a school subject (Hammond, 2004). The lack of research in the field of ICT as a school subject makes it difficult to identify a coherent didactical framework (Dagdilelis, Satratzemi \& Evangelidis, 2004; Hammond, 2005; Markauskaite, 2007; Minaidi \& Hlapanis, 2005; UNESCO 2002; Webb 2002). Indeed, there are a number of issues related to the lack of research in the field of ICT.

First, from the beginning, there have confusion and disagreements among academics and educators about the theoretical foundations of ICT in secondary education. There are divergent opinions on how to define ICT as a subject, in contrast to ICT as a tool, and as a consequence there has not yet been found a coherent theory that takes into consideration the manifold aspects of ICT.

Second, despite the emphasis on a set of well-defined topics, the ICT subject curriculum makes few suggestions as to which didactical skills teachers need to acquire in order to teach these topics. In fact, the didactics of ICT is still in its infancy (Woollard, 2005). It lacks the extensive research base of materials published for the didactics of mathematics or science.

Third, a major problem for teachers is the complexity of software. While know ledge about the principles and functionality of software is necessary for teaching ICT, it is impossible for teachers to know all the specific features offered by the software packages that they use, because software is continually being developed, extended, and improved.

Fourth, a number of ICT topics are more difficult to teach than other subjects, because they require a much greater range of professional and pedagogical skills than those required to teach a unit of work within a specific subject area.

Fifth, it is not yet clear whether the acquisition of programming skills should be included in ICT education. While programming is a difficult matter for novice students because it requires higherorder thinking skills, it is of crucial importance for understanding the nature of computing.

Finally, it is not yet clear whether ICT should be a compulsory subject like mathematics or science. This would have impacted the nature of ICT as a school subject, its content, teaching methods, and assessment procedures.

\section{ICT Didactics: Theoretical Foundations}

The didactics of ICT is a many-sided field of study with a number of theoretical and practical issues. Hence, the most appropriate approach to a careful examination of the didactics of ICT is to question its theoretical foundations and all possible influencing factors connected to it, with the aim of developing a conceptual framework that can be used for the teaching and learning of ICT. The main purpose of the conceptual framework is to help teachers and educators to bridge the gap between theoretical foundations of ICT and teaching and learning processes that take place in classroom (Schulte, 2002; Webb, 2002). Basically, the didactics of ICT has five theoretical foundations (Figure 2):

a) Epistemological foundations

b) Psychological foundations

c) Conceptual foundations

d) Curricular foundations

e) Didactical foundations 


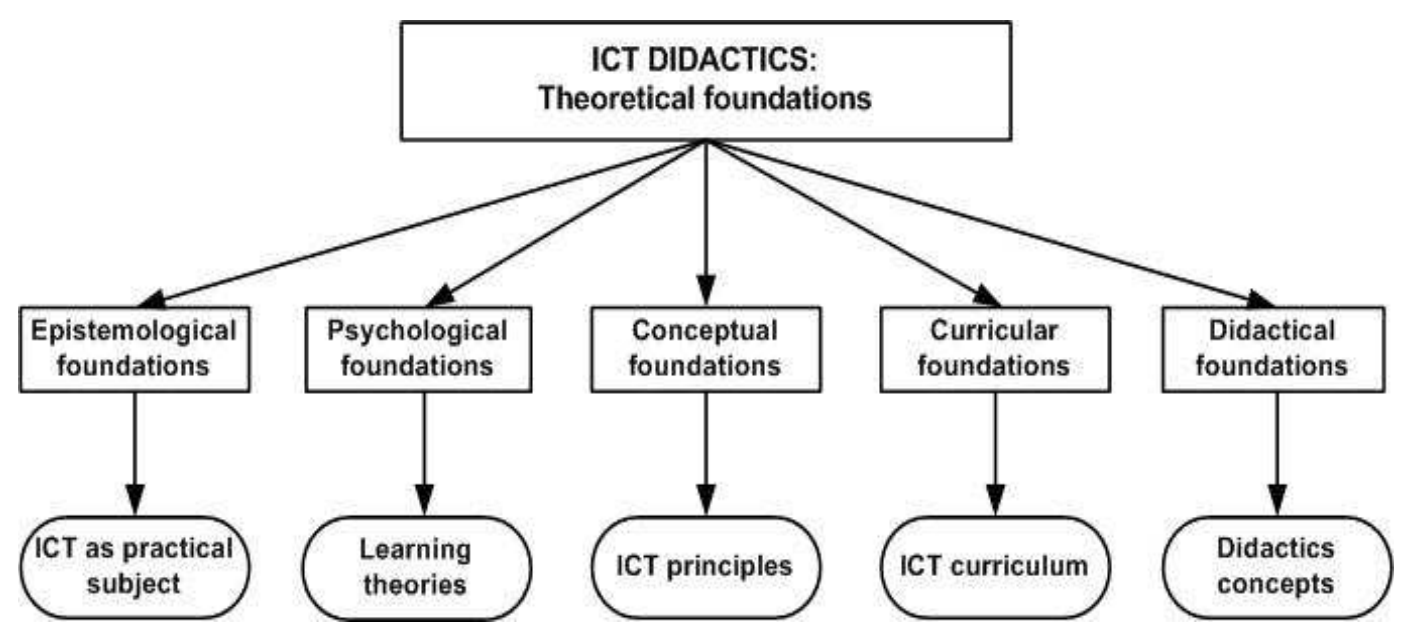

Figure 2: Didactics of ICT: Theoretical foundations

\section{Epistemological Foundations}

According to Trede (2007), the most common epistemological approaches to ICT or similar designations such as "informatics", computer engineering", or "computer science" are threefold:

a) ICT as formal/mathematical science

b) ICT as design/engineering discipline

c) ICT as empirical science

However, despite these categorizations of ICT, the question "what is ICT" is still an unresolved issue, because a number of researchers argue that ICT is a relatively new discipline with its own philosophy, distinct from mathematics, engineering, and science (Coy 1992; Hartmanis 1995; Mingers, 2004; Nauer 1992; Nygaard, 1986; Trede, 2007; Whitaker, 2007; W inograd 1986). Traditionally, ICT is considered as both a formal and an engineering science relying on the traditional scientific paradigm - often called rationalism or positivism (Floyd, Budde, \& Zullighoven, 1992). It shares a lot with mathematics, engineering and science - the scientific method on the one hand and the construction of useful, reliable and cost-effective software tools relying on formal and engineering methods, on the other hand.

The rationalistic paradigm has brought about significant advances in programming methodology and in promoting the development of new software tools. However, rationalism does not provide a sufficient basis for viable decisions in the didactics of ICT, because formal and engineering methods offer little guidance on how to take into consideration educational and didactical issues.

Within the last few years, the constructivist paradigm is increasingly becoming a leading idea and a promising approach to the epistemology of ICT didactics. Constructivism is compatible with main lines of contemporary thought that take counter-positions to rationalistic thinking in ICT education (Hadjerrouit, 2005; Hubwieser, 2004; Schubert \& Schwill, 2004). Basically, constructivism asserts that human beings construct their own knowledge that fits their experiences and prior knowledge rather than describing an objective reality. Constructivism as a philosophical orientation transcends the limitations of the rationalistic view of ICT and provides an adequate epistemological foundation for the teaching and learning of ICT.

Clearly, the constructivist perspective offers a potentially powerful way to rethink the didactics of ICT for many reasons. First, ICT can be considered as a practical, hands-on subject that foc uses both on engineering and empirical aspects. ICT is indeed concerned with the design of software systems based on a set of criteria. Second, ICT as a school subject studies real or artificial phenomenon that 
can be simulated and programmed using computers. It follows that the educational goal of ICT is the construction of software systems through analysis, design, implementation, testing, and evolution of the systems, as well as manipulation of the data produced by the computer. As a result, it appears that the constructivist epistemology fits well with the didactics of ICT since the teaching and learning of ICT primarily emphasize an application oriented point of view, that is to say the construction of software for solving practical problems.

\section{Psychological Foundations: Learning Theories}

Like the field of didactics of mathematics (Jaworski, 1994), the didactics of ICT needs a psychological foundation built on learning theory (Barak, 2006). Psychological foundations reflect views about how learners acquire know ledge and skills.

Given the epistemological foundation of ICT didactics, it appears that the constructivist learning theory is the most appropriate theory that reflects how learners acquire and construct knowledge and skills in the field of ICT. It follows that the psychological foundation of the didactics of ICT is that of constructivism.

Literature reviews suggest that constructivis $m$ can be related to two main commonly accepted paradigms: cognitive constructivis m (Piaget, 1971) and social constructivism (Vygotsky, 1978). From the cognitive constructivist perspective, learning is not a passive transmission of knowledge from the teacher to the student. It is an active construction process in which learners take knowledge, transform and connect it to previously assimilated knowledge and make it theirs by constructing their own interpretation and meaning. Thus, learning is a far more diffuse process than the mere acquisition of explicit know ledge. This view of learning as construction is similar to Levi-Strauss's concept of "bricolage" or tinkering, a "science of the concrete". Bricoleurs construct concepts or theories by arranging and rearranging a set of well-known concrete materials (Levi-Strauss, 1962). This fits well with the view of ICT as a practical subject.

Social constructivism expands Piaget's view of cognitive constructivism, describing learning as a social interaction where the language plays an important role. Accordingly, learning occurs as learners exercise, test, and improve the ir know ledge through discussion, dialogue, collaboration, and information sharing. Vygotsky (1978) argues that the way learners construct knowledge, think, reason, and reflect on is uniquely shaped by the ir relationships with others. Social constructivis $m$ fits well with the construction of software systems performed by a group of students working together.

The literature on debate between cognitive and social constructivism points to the fundamental differences and similarities between them (Lin \& Hsieh, 2001). However, in practice, a mix of constructivist learning theories is being used. Thus, ICT teachers must allow circumstances surrounding the learning situation to help them decide which approach to learning is most appropriate (Karagiorgi \& Symeou, 2005).

\section{Conceptual Foundations: ICT Concepts \& Principles}

ICT as a practical subject deals with the ability to make use of software for problem solving. It requires the acquisition of a number of ICT skills, e.g. analysing the problem, designing a model, understanding the functions and the overall principles of the software, implementing the right sequence of software instructions for problem solving, creating associations in the students' language, transferring previously acquired skills to the software, etc.

However, according to Webb (2002), it is important for teachers not be overwhelmed by trying to master all the details of the software but to focus on the main functions and principles of the software that help to solve the problem. In line with a number of researchers in ICT education 
(Brodahl, Fagernes, \& Hadjerrouit, 2007; Hadjerrouit 2008; Herskin 2004; Mayes \& Fowler, 1999), teaching approaches that are based on the understanding of software principles for problem solving involve three major components:

1) It is important to generate understanding us ing situated examples, visualizations, and dialogues. By using situated examples, the teacher should enable the students to understand the software problem. The principles of the software are then explained through visualizations. Finally, the teacher gives the right sequence of software instructions showing the main implementation steps of the problem solving process.

2) Students use software principles to construct solutions to the problem through involvement in realistic task-based activities. The goal is for students to construct their knowledge and to work at their own pace from their prerequisites. The teacher works as a mentor and guide of learning rather than as a transmitter of knowledge.

3) Students get the opportunity to raise questions regarding the specific problem solving process or more general problems related to software use. Students might for example discuss how the software could be used in similar situations. The teacher can then provide supplementary information.

\section{Curricular Foundations: ICT Literacy}

ICT education in schools has been influenced by the rapid development of ICT literacy of all individuals. ICT literacy describes the ability to develop the potential inherent in ICT and the innovative use of ICT in learning and work activities in society (Erstad 2006; Krumvik, 2006; National

Research Council, 1999). ICT literacy entails a familiarity with ICT and is considered to be a key concept in life long learning. Implicit in the goal of ICT literacy as a continued initiative in education is the realization of the potential of ICT for better learning.

The ICT subject curriculum (ICT Curriculum, 2006) focuses on a set of well-defined topics that is divided in Information Technology I (Digital equipment, programming, multimedia applications, Web development I) and Information Technology II (Information systems design, databases, and Web development II). However, despite the emphasis on a set of well-defined topics, the ICT subject curriculum makes few suggestions as to which skills are needed to realize the potential inherent in ICT for better learning. According to research in the field of ICT literacy (Drenoyianni, 2004; Erstad, 2006; Krumsvik, 2006; Markauskaite, 2007; UNESCO 2002), ICT education should:

1) Promote the acquisition of skills associated with the educational use of ICT in classroom, and involve school teachers and school leaders in the know ledge acquisition process

2) Support teachers to acquire organizational skills, in addition to pedagogical and software skills in order to better integrate ICT into the school environment

3) Help integrate ICT into the heart of the ICT educational system so that teachers and learners feel that ICT skills are an integral part of their competence

4) Develop an extensive research base of study materials that can be accessed and used by teachers in their teaching of ICT and researchers in the ir research work

\section{Didactical Foundations}

In addition to epistemological, psychological, conceptual and curricular foundations, there is a need for a didactical foundation of ICT. The substance of such a foundation is outlined as the reciprocal and interdependent relationships of all the factors influencing teaching and learning processes. Among many approaches to this dimension of ICT, the didactical re lation model is very useful to understand the manifold influencing factors and their relationships (Bjørndal \& 
Lieberg, 1978; Hiim \& Hippe, 1998). The model describes the context (or space) where teaching and learning processes take place. The context assumes that different didactical elements are related to each other, and that there is a reciprocal influence between those elements. The model covers six related factors: Learning outcomes, learners' abilities, structures and resources, content, teaching and learning methods, and assessment procedures (Figure 3):

- Learning outcomes are what the learners should possess after finishing learning activities in terms of concepts, theories, practices, ideas, and principles.

- Learners' abilities are learners' prerequisite knowledge and skills, educational background, as well as personal experiences.

- Structures and educational resources are factors that learners can draw upon to achieve meaningful learning under teacher guidance, such as technical and computer equipment, educational staff, library, books, time table, location, classroom settings, economical conditions, legal and ethical conventions, curriculum, syllabus, etc.

- Learning content is the learning material that is associated with the subject matter, its topics and subtopics, and how these are broken down into lessons.

- Teaching and learning methods are concerned with activities and ways of working, such as lecturing, scaffolding, reading textbooks, doing exercises, performing projects, discussing and collaborating, etc.

- Assessment methods are concerned with the process of assessing the students' learning using assessment procedures, such as oral and written exams, writing a project report, etc.

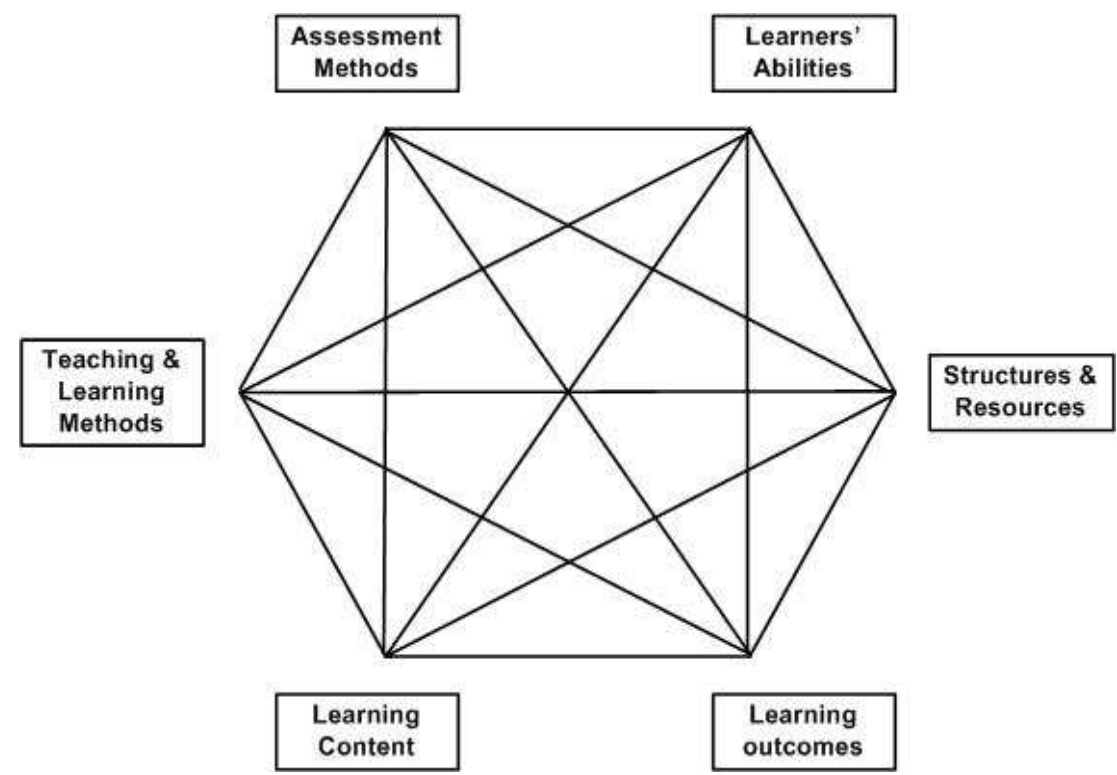

Figure 3: Didactical relation model for planning instruction in ICT

\section{Didactics of ICT: Six Instructional Stages}

The conceptual framework for the didactics of ICT represents an instructional strategy for operationalizing the epistemological, psychological, conceptual, curricular, and didactical foundations described in the previous sections. It consists of six basic stages for facilitating teaching and learning processes. The essential characteristic of the strategy is that it describes a continuous cycle of gradual refinement of teaching and learning activities. Accordingly, this paper proposes a 
teaching strategy, in which six stages are identified - planning, design, instruction, assessment, evaluation, and feedback (Figure 4):

1) The planning stage is concerned with the specification of didactic elements that influence the teaching and learning of ICT.

2) The design stage is characterized by the process of transformation of the know ledge gained in the planning stage into ICT concepts. It consists of three steps: presentation of ICT concepts, construction of the concepts through their use in the performance of meaningful tasks, the testing of the constructed conceptualizations, and the creation of new concepts through dialogue with both fellow learners and instructors.

3) The design stage is followed by the instruction stage, where classroom teaching is performed through the implementation of the design stage.

4) The assessment stage is about assessing the students' learning of ICT concepts and principles using a number of assessment procedures.

5) The evaluation stage is about reflecting on the implementation of the framework in classroom.

6) The feedback stage includes a set of recommendations based on the successes and failures of the evaluation of the framework.

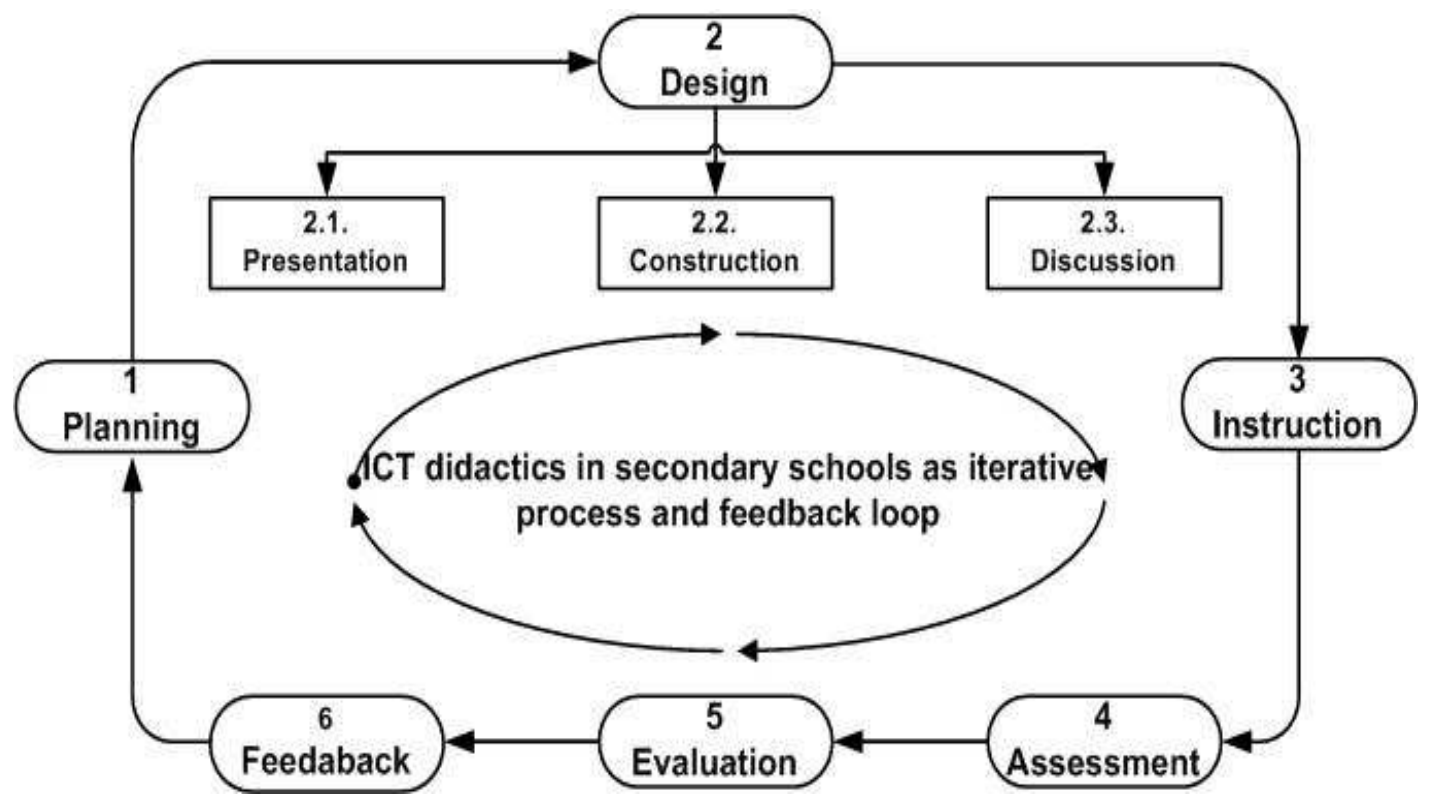

Figure 4: Didactics of ICT as ite rative process and feedback loop with six s tages

\section{Stage 1: Planning}

A crucial concern of ICT is the planning of teaching and learning processes. The planning stage uses general didactical know ledge to specify didactic factors that may influence the teaching and learning of ICT. Hence, this stage is a process of gathering data from the real educational environment.

The didactics of ICT is affected by a number of factors: the current state of the subject matter, the topics and associated skills, the characteristics of teachers and students, learning theories and pedagogical strategies, teaching and learning methods, and assessment procedures. In addition, ICT didactics is influenced by the information technology being used, such as the technical infra- 
structure and online resources, as well as organizational and institutional aspects, including legal and ethical considerations.

The didactical relation model helps teachers to plan the instructional process according to pedagogical criteria. These consist of setting the objectives of the lessons, assessing the existing structures and resources, understanding the students' prerequisite know ledge and skill level, examining the content of the lessons to be taught and its relationships with other content both within ICT and with that of other subjects, specifying teaching methods and assessment procedures. The basic idea of using the didactical relation model is to convert the manifold aspects affecting the teaching and learning of ICT into a set of components: learning outcomes, learner's abilities, learning platform and infrastructure, learning and teaching methods, learning content, and learning assessment.

\section{Stage 2: Design}

The information gained in the planning phase needs to be transformed and converted into knowledge that can be taught. Such a transformation is a necessary step to any attempt to specify in more details teaching and learning processes. The design phase helps teachers to bridge the gap between general didactical knowledge and specific knowledge in ICT. The major advantage of adopting such an approach is that it transposes general didactic knowledge into ICT principles and concepts well understood by teachers. These principles and concepts can be directly applied in the classroom. The transformation process is performed in the design stage. The process itself is based on a pedagogical strategy with tree steps: Presentation, knowledge construction, and discussion.

\section{Step 2.1: Presentation}

The goal of this step is generating understanding of ICT concepts through situated examples, visualizations, and procedure overview. By using situated examples, the teacher should enable the students to understand the problem to be solved using software. The principles of the software are then explained through visualizations. Finally, the teacher gives a procedure overview using visual boxes showing the main implementation steps of the problem solving process. This fits well with the theory of cognitive constructivism.

\section{Step 2.2: Construction}

The objective of the construction step is to let students construct their own knowledge through involvement in realistic problem solving. The aim is to enable each student to construct ICT know ledge at his/her own pace, and from his/her prerequisites. The teacher works as mentor and facilitator of learning, not as a transmitter of knowledge. In addition, students could work together and collaborate in order to improve their learning. This fits well both with the cognitive and the constructivist learning theory.

\section{Step 2.3: Discussion}

In the discussion step, students get the opportunity to raise questions regarding the specific ICT exercises or more general problems about software. The students might also discuss how the software and associated solution could be used and re-used in similar situations. The teacher could then provide supplementary information. In this phase, collaborative learning is done through teacher-managed dialogue with the students. This fits well with the social constructivist learning theory. 


\section{Stage 3: Instruction}

Instruction is the process of implementing the knowledge gained in the design stage. It involves performing a variety of teaching and classroom management activities. In addition, the teaching of ICT in classroom involves a complex arrangement of software resources and online study material, and their didactic configuration and orchestration.

\section{Stage 4: Assessment}

Basically, there are two forms of assessment in ICT education: Summative and formative assessment. Summative assessment is the attempt to summarize the students' learning at some point in time, usually at the end of a course. By contrast, formative assessment occurs when teachers feed information back to students in ways that enable them to learn better, or when students can engage in a similar, self- reflective process. Formative assessment involves asking questions in order to determine the students' current understanding of ICT, so that they can make adjustments if necessary (Beverly \& Bronwen, 2002). This form of assessment is based on the principle that the assessment of learning should not be separated from the learning process. Formative assessment fits well with the view of ICT as a practical subject with a number of task-based activities.

\section{Stage 5: Evaluation}

This phase helps teachers to develop their own ability to self-evaluate their own ICT teaching. During the teaching process, teachers benefit from evaluating and reflecting on how they have achieved their teaching goals. They may ask the following questions: What difficulties were encountered in each stage of the instructional process? What caused the difficulties and how could they be overcome? What general principles may be extracted from the students' learning experiences? What patterns can be perceived in the problems presented in the construction and dialogue steps? Teaching experiences and evaluations often give teachers the necessary pieces of how to perform ICT teaching, but many trainee teachers will not attempt to fit the pieces together unless they are asked specifically to do it.

\section{Stage 6: Feedback}

The feedback stage includes a set of recommendations based on the successes and failures of teaching implementations according to the outcomes of the evaluation stage. Hence, this stage helps teachers to re-plan and re-design their teaching in order to improve its quality.

\section{Five Years of Experimentations with the Framework}

The framework for the didactics of ICT was taught as a compulsory course within the university teacher education programme. Then, it was used by trainee teachers in their teaching practice in secondary schools. Five cycles of experimentations over five academic years (2005-2009) were performed to apply the framework, where the shortcomings of each cycle were identified, redesigned, re-implemented, and re-evaluated.

\section{Methods of Data Collection}

In an attempt to provide a consistent evaluation of the experimentations, this work used the qualitative paradigm (Bryman, 2004), mostly because the experiments focused on trainee teachers' teaching and learning experiences based their perceptions, conceptions, motivations, expectations, thoughts, feelings, and actions in classroom settings within the school context. Accordingly, particular attention was predominantly devoted to three types of evaluation methods and their combination to a multi-strategy of data collection: 
a) Trainee teachers' feedback on their experiences with the framework for the didactics of ICT and associated formal discussions during oral exams, informal discussions with the trainee teachers over a three-month time period and associated data that were collected from short conversations; as well as informal discussions with school teachers (the supervisors of trainee teachers in schools) during meetings organized by the teacher education institution.

b) Analysis and evaluation of trainee teachers' written project reports and associated educational materials that they produced during the experiments, such as teaching practice reports, instructional plans, information about school context, ICT topics and exercises, computer lab assignments, role of school teachers during the experimentations, school students' assessments of teaching sessions by means of survey questionnaires, etc.

c) Field notes and observations of trainee teachers' activities in classrooms during the ir teaching practice in secondary schools; informal discussions with school students and school teachers, who participated in the teaching sessions performed by trainee teachers.

The collection of data was guided by the conceptual framework and associated research questions, which structured what was noticed and paid attention to. The data were organized and categorized according to four issues: The trainee teachers' use of the framework for the didactics of ICT, trainee teachers' personal conceptions about ICT and related issues, contextual factors that affect the application of the framework, and implications of the framework for the teaching and learning of ICT.

\section{Participants}

The experiments, which were performed over a five-year period, are based on three cohorts of participants: trainee teachers, school teachers, and school students between 16-18 years (Table 1).

\begin{tabular}{|c|c|c|c|}
\hline \multicolumn{5}{|c|}{ Table 1: Participants } \\
\hline & $\begin{array}{c}\text { Trainee } \\
\text { teachers }\end{array}$ & $\begin{array}{c}\text { School } \\
\text { te achers }\end{array}$ & $\begin{array}{c}\text { School } \\
\text { students }\end{array}$ \\
\hline Academic Year 2004-2005 & 9 & 11 & 191 \\
\hline Academic Year 2005-2006 & 4 & 4 & 65 \\
\hline Academic Year 2006-2007 & 4 & 4 & 101 \\
\hline Academic Year 2007-2008 & 4 & 4 & 75 \\
\hline Academic Year 2008-2009 & 1 & 1 & 25 \\
\hline
\end{tabular}

\section{Findings}

As mentioned above, the evaluation results were guided by the conceptual framework and associated research questions. Hence, the findings describe the degree of application of the framework for the didactics of ICT, the personal perceptions and associations which trainee teachers made about the value of the framework, the contextual factors that influenced the application of the framework, and, finally, the implications of the framework for the learning and teaching of ICT. The findings are described with respect to the experiments that were carried out in the academic year 2004-2005, 2005-2006, 2006-2007, 2007-2008, and 2008-2009. 


\section{Degree of Application of the Framework}

This evaluation was investigated in terms of trainee teachers' degree of application of the six stages of the framework. This evaluation was based on data from project reports, formal and informal discussion with trainee teachers, and feedback on their experiences during oral exams.

\section{ICT teaching subjects in 2004-2005}

In the academic year of 2004-2005, the following ICT teaching subjects were taught by 9 different trainee teachers in 9 different schools:

- Programming with Visual Basic

- Creating diagrams using the spreadsheet program MS Excel

- Web design and development with MS FrontPage

- Connecting databases to Web sites using the database program MS Access 2000 and the web editor MS FrontPage

- Data modelling with the database program Modelator and MS Access

- System development with the project management tool MS Project

- Drawing figures using the photo imaging software Adobe Photoshop 6.0

- Societal implications of information and communication technologies

- Software and hardware components of information technology

The following outcomes demonstrate the degree to which the six stages of the framework were fulfilled in the first experiment.

1) Most trainee teachers did not plan the ir lessons in complete accordance with the didactical relation model.

2) Most teachers did not design their teaching according to the presentation step of the design stage with the aim of generating understanding of ICT concepts and principles.

3) The dialogue step of the design stage suffered from insufficient students' feedback.

4) It turned out to be a problem for the trainee teachers to critically evaluate their teaching experiences.

5) Trainee teachers did not pay attention to the feedback stage.

6) A number of teachers did not take into consideration the specific needs of school students.

7) Only two teachers went through the first four phases of the instructional strategy. As a result, none of the trainee teachers implemented the framework in total compliance with its underlying principles.

\section{ICT teaching subjects in 2005-2006}

In the academic year of 2005-2006, the following ICT teaching subjects were taught by 4 different trainee teachers in 4 different schools:

- Data modelling using the database program MS Access 2000 and Visual Basic

- Web design with the Web editor MS FrontPage; Internet and electronic communication 
- Using the Learning Management System (LMS) Classfronter and document design with MS PowerPoint

- Using the Graphic Editor Adobe PhotoShop and the Image Manipulation Program GIMP

Compared with the first experience, all trainee teachers who conducted the second experiment did make progress in their efforts to implement the framework. They paid more attention to planning, design, instruction, and assessment stages than teachers from the first experiment. This progress can be explained by three factors.

1) Pre-work and preparation of trainee teachers before entering the field of teaching practice.

2) The availability of documented experiences from the first implementation of the framework, which could be reused with some modifications.

3) Trainee teachers' prior pedagogical experiences and ICT skills.

However, despite important improvements, trainee teachers needed to make progress in their attempt to evaluate their own teaching for the purpose of redesigning the implementation of the framework. In addition, the planning needed a holistic analysis of all the elements that must be considered in the teaching process.

\section{ICT teaching subjects in 2006-2007}

In the academic year of 2006-2007, the following ICT teaching subjects were taught by 4 different trainee teachers in 4 different schools:

- Web design with the Web editor MS FrontPage 2003

- Programming with HTML, publishing and maintaining Web sites

- Data modelling with the database program MS Access 2003

- Using the spreadsheet tool MS Excel in science and mathematics

The third experience did not reveal significant progress compared with the second experiment, with the exception of redesigning the teaching of ICT according to the evaluation phase. Unfortunately, this was the case of only one trainee teacher. Nevertheless, the third experiment confirmed the fact that the reuse of previous project reports and documented experiences helped the trainee teachers to better apply the framework. Clearly, the availability of teaching resources, pre-work, and preparation were important factors of success in applying the framework for the didactics of ICT for the third time.

\section{ICT teaching subjects in 2007-2008}

In the academic year of 2007-2008, the following ICT teaching subjects were taught by 4 different trainee teachers in 4 different schools:

- Using Dreamweaver CS3 and Flash CS3 professional for designing Web shops

- Formatting sound effects using the Audacity program.

- Using Adobe Flash CS3 and Adobe Dreamweaver CS3 for Web design

- Using Windows Server 2003 and Active Directory for managing and maintaining files

The fourth experiment confirmed the fact that the reuse of previous project reports and documented experiences helped the trainee teachers to better apply the framework from the planning to the assessment stage. In addition, it appears that the role of the instructor was an important factor that affected trainee teachers' learning processes. Indeed, the gradual change of emphasis 
from "teaching" to "guiding and collaborating" reduced the amount of lecture notes, overheads, and handouts. This helped the instructor to spend more time both face-to-face and online. This, in turn, improved the collaboration with the trainee teachers. However, despite significant improvements, it turned out to be a problem for most trainee students to redesign their teaching due to the school timeframe, which had not been in line with the trainee teachers' six weeks practice.

\section{ICT teaching subjects in 2008-2009}

In the academic year of 2008-2009, the following ICT teaching subjects were taught by one trainee teacher in one school:

- Web design with the Web editor Dreamweaver 2004

- Data modelling with the database program MS Access 2003

Complete data are not yet available regarding the fifth experiment. However, it can be mentioned that this experiment will take into account the weaknesses and problems of previous experiences in an attempt to improve the application and evaluation of the framework. Particularly important are school students' assessments of the framework by means of survey questionnaires, as well as trainee teachers' recommendations based on the successes and failures of the implementation of the framework according to the outcomes of the evaluation stage. Recommendations will help future trainee teachers to re-plan and re-design their teaching in order to improve its quality.

\section{Influencing Factors}

A variety of factors, which affected trainee teachers' implementations of the framework for the didactics of ICT, were borne out of the teaching experiences and classroom practices. These are divided into two broad categories: contextual factors and personal factors.

\section{Contextual factors}

Formal and informal discussions with the trainee teachers, feedback on their experiences during the oral exam, field notes and observations of their teaching practices in classroom, and analys is of project reports revealed that a number of contextual factors affected the trainee teachers' practices of the framework in secondary schools. These are:

- School context

- School teachers' supportive role

- Trainee teachers' training and preparation

- School students' motivation and know ledge level

- ICT as a subject of study

- ICT as compulsory subject at the secondary school level

- Availability and accessibility of learning resources

$\underline{\text { School context. }}$. Observations of teaching practices revealed that secondary school classrooms were tightly regimented by a timetable and a number of organizational factors that could constrain the experimental sessions within the framework (Valcke et al, 2007). Indeed, a number of trainee teachers felt that the timetable and ICT syllabus did not always allow sufficient time for using the framework. A number of trainee teachers regarded the framework as an add-on or as a sometimes unnecessary intervention, because it was not made available to the school students in the exam. As a result, a number of trainee teachers reported that the school context could act as a barrier that prevents them from trying out the framework as originally expected. However, trainee 
teachers, who negotiated timetable with their supervisors, were in a better position to implement the framework.

School teachers' supportive role. Observations of ICT lessons and discussions with school teachers indicated that their attitudes, concerns, and beliefs could affect the implementation of the framework in ways that were consistent with instructional practices at their schools. However, school teachers' support was an important condition for encouraging trainee teachers in their efforts to apply the framework in their classrooms. The importance of school teachers in promoting trainee teachers' experimentations was more visible in the second and third experiments. The active involvement of school teachers did not mean they understood all the potentialities of the framework for the didactics of ICT. Nevertheless, their supportive role was of great importance for trainee teachers. However, this was not always the case, especially for those who were considered as conservative teachers or those who were intellectually not engaged in the experimentations.

Trainee teachers' training and preparation. When applied for the first time in 2005, trainee teachers were introduced to the basics of the framework for the didactics of ICT three months before entering the field of teaching practice. Most teachers soon realized that a considerable amount of personal time was needed to be spent in order to familiarise themselves with the framework. Thus, the process of acquiring knowledge of the framework was time-consuming and that the lack of time to get acquainted with the framework was one of the obstacles that stood in trainee teachers' ways of using the framework as originally anticipated. Based on the first experiment, the training of teachers was then improved by integrating situated examples and applications of the framework. The training received was then identified by the participating trainee teachers from the second and third experiments to have contributed to a better understanding of the framework, and to have provided them with ideas on how to apply the framework more efficiently. Nevertheless, trainee teachers suggested that they could benef it from more technical and pedagogical support according to the ir skill levels and prerequis ites. Some teachers also felt that they needed support from professionals (experienced people in the field of ICT teaching, e.g. experienced school teachers) to obtain more information on how the framework for the didactics of ICT could be applied more efficiently.

School students' motivation and knowledge level. School students' motivation was another important factor that could promote or inhibit the potentialities of the framework. It has been observed that students with insufficient motivation did not learn ICT concepts and principles as expected or required by the trainee teacher. Those students were not able to work on their own solving software problems. Some became completely dependent on the teacher's help. On the other hand, motivated students were better in their efforts to acquire ICT knowledge.

ICT as compulsory subject. A number of trainee teachers pointed out to the need of having ICT as a compulsory subject that is embedded in the secondary school scheme of work. They believed that it would be easier to introduce innovative frameworks for the didactics of ICT, as the one presented in this paper, if the subject matter was a compulsory subject. However, currently no secondary school includes ICT as a compulsory subject.

ICT as a subject of study. Some schools did not offer ICT as a subject of study, because ICT was not implemented at those schools. As a result, a number of trainee teachers had to adapt the framework to the school specificities and the subjects offered by the schools. The supportive environment of the schools for this kind of ICT use was a necessary condition for helping trainee teachers in their efforts to implement the framework. Clearly, even if ICT was not a subject at their schools, the existing ICT policy and the positive attitude of the school leaders contributed to the success of the framework. Unfortunately, this was not the case for conservative schools that 
did not see the added value and the benefit of the framework for the didactics of ICT. This attitude might have, to some degree, discouraged experimentation with the framework.

Availability and accessibility of learning resources. Trainee teachers reported that that the lack of learning resources could act as a barrier to the use of the framework for the didactics of ICT. The lack of documented experiences and situated examples was clearly an obstacle that prevented teachers from the first experiment to apply the framework as originally expected. As a consequence, trainee teachers mixed existing textbooks in ICT with study material that they produced for the purpose of the experiments.

\section{Personal factors}

Observations of trainee teachers' teaching practices, as well as formal and informal discussions indicated that their personal perceptions of the software being used in classroom, the ir preunderstanding of the existing school practices and their interpretations of the ICT subject curriculum, their conceptions of the nature of ICT, and their pedagogical knowledge affected the use of the framework in secondary schools. Accordingly, the following personal factors can be distinguished:

- Trainee teachers' perceptions of the software being used in classroom

- Trainee teachers' perceptions of ICT curriculum and existing school practices

- Trainee teachers' perceptions of ICT as a school subject

- Trainee teachers' perceptions of pedagogy and pedagogical experience

The first category of personal factors comprised perceptions that a trainee teacher holds about his/her own software knowledge background, familiarity with software tools, features and functionality, as well as their limitations and potentialities. While trainee teachers did not feel that they had to know everything the software potentially can do, they did not deny the importance of the need to familiarize themselves with the software to the extent of knowing what their functionalities and features are and how to use them for solving problems. However, most trainee teachers believed that pre-work and preparation for using the software before entering the field of teaching practice would have helped them to tackle the difficulties related to the technicalities of software. Furthermore, some teachers felt that teacher education should involve more than the theoretical understanding of software principles. Some teachers admitted that it is not necessary to make room for learning the technicalities of software since teacher education requires that trainee teachers should have sufficient prerequis ite knowledge in software technicalities in order to concentrate on what really matters: the acquisition of didactical know ledge and cognitive skills. Nevertheless, there was evidence in the data collected that some trainee teachers needed knowledge of the technical aspects of ICT and that the participating teachers' levels of ICT knowledge and skills varied. The data indicated that a number of teachers were not always comfortable with the software tool they used in their teaching. On the other hand, teachers with solid background in ICT and sufficient pedagogical knowledge were more confident in their attempt to apply the framework for the didactics of ICT according to its principles.

The second category of personal factors consisted of trainee teachers' perceptions of the National Curriculum Recommendations regarding the use of ICT as a school subject (ICT curriculum, 2006), and perceptions of the existing school practices in ICT education. Indeed, apart from the training received at the university level, most teachers also reported that they spent a considerable amount of time familiarising themselves with the ICT applications existing at their schools. A number of trainee teachers felt that this was a necessary step to any attempt to implement the framework for the didactics of ICT. Being familiar with existing practices and applications in ICT enabled them to adapt and integrate the framework within the existing scheme of work. In addi- 
tion, the analysis of trainee teachers' implementations revealed that the National Curriculum Recommendations allowed a wide range of different interpretations. This was not surprising, because the topics specified in the National Curriculum are not precise enough about teaching methods. Its poor specification may have contributed to a wide range of interpretations of the text on what it is supposed to teach and how to teach ICT. When examined in more details the National Curriculum focuses almost exclusively on learning outcomes rather than teaching methods and didactical skills. This was clearly reflected in the project reports as these indicated a variety of interpretations and, sometimes, a lack of reflection on teaching methods.

The third category of personal factors was trainee teachers' perceptions of ICT as a school subject, which also affected their thinking about the use of the framework for the didactics of ICT. For example, for those teachers whose view of ICT was more textbook-centred, focusing more towards carrying out textbook-tasks in their ICT teaching, gave their school students a textbookbased view of ICT that can be applied in a more top-down way. On the other hand, those trainee teachers who viewed ICT as a practical subject moved beyond ICT teaching based on textbooktasks, focusing more on practical, intrinsically motivating applications and situated examples, letting their students freely explore the capabilities of the software for solving the applications and exercises. It appeared that those teachers considered ICT as a practical subject, emphasizing more the bottom-up approach of solving problems with the computer.

The fourth category of personal factors was concerned with trainee teachers' perceptions of pedagogy and pedagogical experience, which also affected their thinking about the application of the framework. Observations and analys is of project reports revealed that trainee teachers' personal pedagogical strategies and their own learning experiences of ICT teaching were reflected in their attempt to apply the framework and their expectations of the school students' learning of ICT. Often, they had to adapt the framework to some of the characteristics of their students, such as taking into account their skill level and prior knowledge. Contrary to trainee teachers without sufficient pedagogical experiences, those other teachers who viewed teaching from a constructivist point of view, allowed their students freely construct their own know ledge according the ir own skill level and prerequis ite know ledge in ICT.

\section{Discussion}

In this section, a summary of findings that resulted from the application of the framework for ICT didactics are presented. The implications of the framework and recommendations for future research work and experiments are discussed as well.

The findings help to answer the four research questions:

1. How do trainee teachers use the framework in the ir teaching of ICT in secondary schools?

2. How do trainee teachers' personal perceptions of ICT affect the use of the framework in secondary schools?

3. What are the contextual factors that emerge as influential on trainee teachers' uses of the framework?

4. What are the implications of the framework for the teaching and learning of ICT in secondary schools?

\section{Summary of Findings}

The analysis of trainee teachers' implementations of the framework for ICT didactics resulted in the following findings: 
- Trainee teachers who conducted the first experiment did have difficulties in applying the framework according to its principles for many reasons: Lack of pre-work and preparation, lack of supportive study material, lack of school teachers' support and supervis ion, lack of ICT skills and pedagogical know ledge. The implementation of the framework improved gradually due to the reuse of teaching experiences. As a result, trainee teachers who conducted the second, third, and fourth experiment were more successful in the ir efforts to use the framework. Data from the fifth experiment are not yet available.

- The implementation of the framework was influenced by contextual factors that affected a number of elements. These factors were: school context, such as timetable and ICT syllabus, school teachers' supportive role, school students' motivation and knowledge level, trainee teachers' training and preparation, school ICT as compulsory subject, ICT as a subject of study in secondary schools, and the availability and accessibility of learning resources. Some of these elements can act as inherent barrier to trying out the framework.

- The use of the framework was influenced by personal factors that affected a number of dimensions. These factors include trainee teachers' perceptions of pedagogy and pedagogical experiences, perceptions of the ICT subject curriculum and existing school practices, skill level and know ledge background of the software being used, and perceptions of the nature of ICT as a school subject. These factors can inhibit or promote the use of the framework.

\section{Implications for ICT Didactics}

This paper proposes an innovative framework for the didactics of ICT, which takes into consideration epistemological, psychological, conceptual, curricular, and didactical elements connected to the teaching and learning of ICT as a way of solving current deficiencies of ICT teaching at the secondary level. From a theoretical point of view, the proposed framework has a great potential for transforming existing pedagogies in ICT and push ahead with innovative pedagogies. It could have positive impacts on teaching and learning processes if secondary schools realize that the framework offers affordances to overcome some of the current deficiencies of ICT pedagogies. However, from a practical point of view, the didactics of ICT in secondary education is a complex task. It can only succeed if all possible influencing factors, both personal and contextual, are taken into account. From these considerations, some implications for the teaching and learning of ICT can be drawn. These are related to planning issues, conceptual understanding of ICT, learning issues, differentiation and misconceptions, practical issues, and assessment considerations.

\section{Planning issues}

Before teaching, trainee teachers were supposed to plan their lessons in ICT. Usually, planning involves examining the content within the ICT subject to be taught and eventually its relationships with other content, as well as considering teaching methods and assessment procedures. Normally, trainee teachers start with textbooks available at schools, previous teaching material, and recommendations of the National curriculum. There are a number of problems associated with this approach. First, an examination of the National Curriculum reveals that methods of teaching and assessment are not well-specified. The curriculum focuses exclusively on content and learning outcomes rather than teaching methods. Second, trainee teachers need to consider how the content of the ICT subject is related to that in other subject areas because the teacher may be expected to plan to teach this content in conjunction with a content from another subject area, e.g. science or mathematics. However, ICT textbooks available at schools cannot provide appropriate help as these are exclusively related to specific content in ICT. In addition, many trainee teachers lack methodological knowledge about how to connect ICT to another subject, because they lack specific training and qualifications to teach ICT in connection to another subject. 
An important implication of this study is that the teaching of ICT requires a much greater range of professional and pedagogical skills than that required to teach a unit of work within a specific subject area, for example mathematics or science (Webb, 2002). It is thus important for teachers to be aware of the lack of knowledge needed to connect ICT to other subject areas.

\section{Conceptual understanding of ICT}

The basic idea of the framework for the didactics of ICT is underpinned by an understanding of ICT concepts and principles. Even if ICT is considered as a practical subject, it cannot be learned solely through interaction with a computer and trial-error working. The teaching of ICT must be based on principles. However, teaching ICT through the presentation of ICT concepts and principles is not an easy task. A major problem is the complexity of the features and functionality of the software and how to present them to the students. However, it is almost impossible for ICT teachers to know all the specific features of all the software packages that they use, because the software is continually being developed and improved (Hammond, 2004; Webb, 2002). Clearly, the rapidly changing nature of software makes it difficult for novice trainee teachers to identify software principles. Of course, teachers don't need to know all the features of all the software as long as they know to find out about these features and associated principles, and situated examples explaining these principles and features. For example, when explaining Web editors to students, trainee teachers need to have an overview of the principles underlying Web editors. However, an examination of the activities performed revealed that some trainee teachers lack knowledge on how to transform the content of the subject matter to concepts and principles that can be taught. Clearly, it was not always easy for trainee teachers to think about principles and situated examples, especially when they were confronted with the task of using a new software package.

An important implication of this study is that both teacher education and teaching practice in secondary schools need to emphasize know ledge and qualifications that enable trainee teachers to identify the underlying principles of software using multiple forms of representations, especially visualisations. Trainee teachers also need to identify suitable contexts for the application of software principles using situated examples that may be taken from the school context or the wider community.

\section{Learning issues}

A great deal of research has focused on theories of learning in relation to information and communication technology (ICT). However, research focused mostly on using ICT as a tool rather than learning ICT as a subject. For example, Papert's work on the turtle micro-world of LOGO argues that constructionism (Papert, 1980), a subset of Piagets' cognitive constructivism (Piaget, 1971), helps students to learn ICT. This has to a certain degree influenced the ways of teaching ICT as a subject. However, teachers should not take for granted that cognitive constructivist approaches are the only way of teaching ICT. Indeed, it seems that a combination of learning theories is more appropriate for teaching ICT as a subject. An examination of the trainee teachers' experiences with the framework for the didactics of ICT revealed that both cognitive and collaborative learning theories could play a key role in the teaching and learning of ICT. Of course, the cognitive learning theory should be the very basis for generating understanding through the presentation of ICT concepts and principles. On the other hand, social constructivism and situated learning theories (Ben-Ari, 2004) are more appropriate to promote collaborative learning both in the construction and dialogue steps of the framework (McDougall \& Boyle, 2004). It is indeed useful to let school students collaborate in the construction phase. This might mean fewer differentiations for the students, but social constructivism will increase the learning by collaboration in a higher degree. 


\section{Differentiation and misconceptions}

Differentiation is still an important issue of teaching ICT. It involves fitting the material to the characteristics of the school students, taking into account their abilities, gender, language, culture, motivation, prior know ledge, and skills. The issue of misconceptions is directly related to differentiation. Whereas there is an extensive research base of misconceptions in other subject areas, there is a lack of research in the field of ICT (Ben-Ari, 2001; Ben-David Kolikan \& Pollack, 2004). Teachers need to take into consideration students' misconceptions about computers, because the hidden nature of the mechanisms of software provides the potential for misconceptions, mostly because students expect computers to behave as human beings (Dagdilelis, Satratzemi, \& Evangelidis, 2004). Misconceptions are persistent and can inhibit or even hinder conceptual understanding of ICT. Hence, trainee teachers need to be aware of misconceptions. Unfortunately, most of them are not well prepared to research students' understanding of software, analyse their thinking, identify misconceptions, and then design teaching cases that would build on students' prior know ledge and help them to reflect on and restructure their views of ICT. An important implication of this work is that more research is needed to determine the extent and nature of misconceptions in the field of ICT.

\section{Practical issues}

The findings revealed the very pragmatic approach to teaching ICT that a number of trainee teachers had adopted in the second and third implementation of the framework. Many teachers aimed to provide a mix of whole-class teaching and hands-on activity, and a further mix of teacher direction and student exploration. Overwhelmingly, those trainee teachers associated ICT with being a practical subject because it was a "hands-on" subject in which school students generally spent a lot of time interacting with the computer, not only in the knowledge construction step when they tried to solve practical problems, but also in other phases of the instructional process. In line with the research literature (Hammond, 2004), the practical nature of ICT has contributed to increase trainee teachers' motivation to teach ICT.

However, trainee teachers were confronted with a number of problems and several constraints associated with contextual factors, such as the pressure of time for preparation and updating of know ledge. One of the problems was the tension between the teacher's desire to guide students in their learning and to provide opportunities for learning in an independent and undirected manner. On the one hand, trainee teachers felt that they need to help their students to understand ICT concepts and principles. On the other hand, students were more focused on trial-error-working both individually and in group. As a result, it was not easy for trainee teachers to find the right balance.

\section{Assessment considerations}

Assessment is one of the most important and difficult aspects of the educational process, because assessment and instruction are inextricably linked (Webb, 2002). An important issue of assessment is that students need to work independently to produce solutions based on analysis and design of software. Hence, a crucial question is how to assess the students' learning. The National Curriculum reveals that it does not provide assessment procedures. In addition, existing assessment practices based on summative procedures alone are not appropriate to assess the learning effects of the framework for the didactics of ICT in the long term, as the trainee teachers' experiences clearly demonstrated.

In order to develop appropriate assessment procedures, trainee teachers need to create motivating task-based activities through situated examples where students feel confident to work on new, but similar, situations. These situations should enable trainee teachers to predict problems and ques- 
tions that help students to make progress in applying well-proved solutions to new situations through analogical thinking and reuse skills. Trainee teachers need to assess students' learning difficulties throughout the instruction process as well as through a range of open-ended questions and instructional strategies that might help students to think about the nature of the problem, and the value of strategies for tackling the problem.

\section{Evolution of the Framework}

The framework for the didactics of ICT outlined in this paper evolved from an initial instructional approach to ICT to a more sophisticated framework the last five years through cycles of experimentations, evaluations, and redesigns, where the shortcomings of each cycle were identified and improved. The gradual changes of the framework were a general process that affects the framework's foundations and features. Since the academic year of 2005-2006, the framework has evolved through the influence of four factors: the ICT subject, the availability of online resources, trainee teachers' successive experimentations and evaluations, and the instructor's role.

First, the ICT subject, which enables the use of a common set of terms throughout the whole training process, affected the framework for the didactics of ICT. As a result, it has been easier for trainee teachers, having a university degree in ICT, to move from ICT at a higher educational level to ICT in secondary schools as far as the technicalities of software were concerned.

Second, the gradual evolution of the framework occurred through the accessibility of online resources that trainee teachers may use, modify, adapt, and reuse with slight modif ications in order to perform their own implementations of the framework. This occurred through the online access to teachers' project reports from past versions of the didactics course, examples of practice reports, examples of lesson plans based on the didactical relation model, and interactive software applications at schools. This use of online resources fostered the acquisition of reuse and analogical thinking skills, such as comparing, contrasting, and recognizing similarities and differences between new project situations and previous project solutions, as well as modifying and reusing existing solutions.

Third, the framework evolved through successive trainee teachers' evaluations and critical reflections. Trainee teachers' evaluations by means of project reports, formal and informal discussions with the instructor and school teachers, as well as assessment of the school students' learning by means of standard questionnaires were becoming an important tool for improving the quality of the framework.

Fourth, the role of the instructor was another important factor that affected the evolution of the framework. After the first year of experimentation, the instructor gradually shifted from the teacher as the center of knowledge to the position as facilitator of learning. Dia logue with trainee teachers was becoming one the primary vehicles used to negotiate project work, and less the preparation of study material and information resources. Hence, the change of emphasis from "teaching" to "facilitating, guiding, and collaborating" reduced the amount of lecture notes, overheads, handouts and lesson plans. But, in contrast, the instructor had to spend more time face-toface and online, collaborating with trainee teachers, asking and answering questions, providing feedback, and assessing their learning.

To sum up, various factors influenced the evolution of the framework by improving its overall design. The evolution of the framework occurred over a timescale of five academic years and will continue in the future. The current framework seems to be more robust and better suited to the trainee teachers. 


\section{Conclusions and Future Work}

The aim of this research was to gain an understanding of trainee teachers' applications of an innovative framework for the didactics of ICT, the role of personal and contextual factors in implementing the framework at the secondary school level, and to find out how these factors influence the use of the framework over a period of three years.

As with all educational research of this nature, it is difficult to conclude direct causality between the characteristics of the framework for the didactics of ICT and trainee teachers' implementations in schools. By considering the various personal and contextual influences on the teachers, it is possible to make some reasonable interpretations of the findings. The findings of the study indicate that trainee teachers' implementations evolved from simply applying some the framework's principles without a clear understanding of the nature of the framework to a better mastering and involvement in the school context. Trainee teachers from the second and third and fourth experiment became more confident in their attempts to apply the framework in compliance with its principles. Looking closely to some of the findings, it appears that a number of trainee teachers liked the framework and its underlying principles even if it was demanding in terms of implementation efforts. In addition, trainee teachers who conducted the second, third, and fourth experiment showed a more positive evaluation of the framework. As a result, they became more aware of the potential and opportunities that the framework can offer in their ICT teaching at the secondary school level.

Of course, radical didactical and pedagogical changes are difficult to achieve in the ir teaching practice of six weeks. Besides personal and contextual factors that can act as inherent barriers to trying out the framework for the didactics of ICT, working simultaneously as trainee teacher and researcher are challenging tasks for most trainee teachers to deal with in classroom.

Concerning the implementation of the framework, a number of suggestions and ideas emerged from the experimentations in 2005-2009. First, trainee teachers must be convinced of the need for pedagogical change in ICT teaching and how change can be incorporated into their teaching practice. Second, it is an advantage that trainee teachers have solid background in ICT and sufficient pedagogical knowledge in order to be able to successfully apply the framework for the didactics of ICT. Third, trainee teachers should develop the ir ICT teaching in a way that motivates school students, enriches learning and stimulates high-level thinking and reasoning. Fourth, it would be helpful to consider ICT as a practical subject and let students explore the capabilities of computers in conjunction with software principles, situated and motivating examples. Fifth, trainee teachers must be aware of contextual factors that directly or indirectly affect the implementation of the framework in order to be in a better position to negotiate timetable, syllabus, as well as practical and organizational issues. Hopefully, these suggestions will benefit future trainee teachers and school teachers in ICT. It is also believed that this research will provide useful information for researchers in the field of ICT.

In future research, it is intended to develop a better instrument to assess trainee teachers' perceptions of the conceptual framework for the didactics of ICT and the factors influencing the implementation of the framework in secondary schools. Finally, continuous cycles of new experimentations with the framework in future studies according to the design-based research paradigm, are warranted to generalize the findings of the present work. 


\section{References}

Barak, M. (2006). Instructional princip les for fostering learning with ICT: Teacher's perspectives as learners and instructors. Education and Information Technologies, 11, 121-135.

Barab, S., \& Squire, K. (2004). Design-based research: Putting a stake in the ground. The Journal of Learning Sciences, 13(1), 1-14.

Bell, P. (2004). On the theoretical breath of design-based research in education. Educational Psychologist, 39(4), 243-253.

Ben-Ari, M. (2001). Constructivism in computer science education. Journal of Computers in Mathematics and Science Teaching, 20(1), 45-73.

Ben-Ari, M. (2004). Situated learn ing in co mputer science education. Computer Science Education, 14(2), $85-100$.

Ben-David Kolikant, Y., \& Pollack, S. (2004). Establishing computer science norms among high school students. Computer Science Education, 14(1), 21-35.

Beverly, B. F., \& Bronwen, C. (2002). Formative assessment and science education. London: Kluwer Academic.

Bjørndal, B., \& Lieberg, S. (1978). New ways of thinking in didactics [in Norwegian. Orig inal title: Nye veier i didaktikken]. Oslo: Aschehoug.

Brodahl, C., Fagernes, M. \& Had jerrouit, S. (2007). Applying and evaluating understanding-oriented ICT user training in upper secondary education. Issues in Informing Science and Information Technologies, 4, 473-490. Retrieved June 12, 2008 from http://proceedings.informingscience.org/InSITE2007/IISITv4p473-490Brod287.pdf

Bry man, A. (2004). Social research methods (2nd ed.). New York: Oxford University Press.

Coy, W. et al. (Ed.). (1992). Conceptions of informatics [in German. Orig inal title: Sichtweisen der Informatik]. Berlin: Vieweg.

Dagdilelis, V., Satratzemi, M. \& Evangelidis, G. (2004). Introducing secondary education students to algorithms and programming. Education and Information Technologies, 9(2), 159-173.

The Design-Based Research Collective. (2003). Design-based research: An emerging paradig m for educational inquiry. Educational Researcher, 32(1), 5-8.

Drenoyianni, H. (2004). Designing and implementing a project-based ICT course in a teacher education setting. Rewards and pitfalls. Education and Information Technologies, 9(4), 387-404.

Erstad, O. (2006). A new direction? Digital literacy, student participation and curriculu m reform in Norway. Education and Information Technologies, 11, 415-429.

Floyd, C., Budde, R., \& Zullighoven, H. (1992). Software development and reality construction. Berlin: Springer Verlag.

Gonzales, G. (2004). Constructivism in an introduction to programming course. JCSC, 19(4), 299-305.

Hadjerrouit, S. (2008). Using a learner-centered approach to teach ICT in secondary schools: An exploratory study. Issues in Informing Science and Information Technology, 5, 239-256. Retrieved October 24, 2008 fro $\mathrm{m}$ http://proceedings.informings cience.org/InSITE2008/IISITv5p233-259Hadj424.pdf

Hadjerrouit, S. (2005). Object-oriented software development education: A constructivist frame work. Informatics in Education - An International Joumal, 4(2), 167-192.

Hammond, M. (2004). The peculiarities of teaching information and communication technology as a subject: A study of trainee and new ICT teachers in secondary schools. Technology, Pedagogy and Education, 13(1), 29-42.

Hartmanis, J. (1995). Turing award lecture: On computational complexity and the nature of computer science. ACM Computing Surveys, 27(1), 7-21. 
Herskin, B. (2004): IT-training - The user in the centre (in Danish. Original title: IT-undervisning - med brugeren i centrum). København: Nyt Teknisk Forlag.

Hiim, H., \& Hippe, E. (1998): Instructor guidance in the education of teachers related to vocational subjects [In Norwegian: Undervisning splanlegging for yrkeslarere]. Oslo: Universitetsforlaget.

Hubwieser, P. (2004). Didactics of informatics: Basics, concepts, examples [in German. Original title: Didaktik der Informatik: Grundlagen, Konzepte, Beispiele]. Berlin: Springer Verlag.

ICT Curriculum 2006. Retrieved September 14, 2008 from http://www.utdanningsdirektoratet.no/templates/udir/TM Læreplan.aspx?id=2100\&laereplanid=173746

Jaworski, B. (1994). Investigating mathematics teaching: A Constructivist enquiry. London: The Falmer Press.

Karagiorg i, Y., \& Sy meou, L. (2005). Translating constructivism into instructional design: Potential and limitations. Educational Technology \& Society, 8(1), 17-27.

Kru ms vik, R. (2006). The dig ital challenges of school and teacher education in Norway: So me urgent questions and the search for answers. Education and Information Technologies, 11, 29-256.

Lin, B., \& Hsieh, C. (2001). Web-based teaching and learner control: A research review. Computers \& Education, 37(3-4), 377-386.

Levi-Strauss, C. (1962). The savage mind [in French. Original title: La pensée sauvage]. Paris: Librairie Plon.

Markauskaite, L. (2007). Exp loring the structure of trainee teachers' ICT literacy: The main co mponents of and relationships between, general cognitive and technical capabilities. Educational Technology Research and Development, 547-572.

Mcdougali, A. \& Boyle, M. (2004). Students strategies for learning computer programming: Implications for pedagogy in informatics. Education and Information Technologies 9(2), 109-116.

Mayes, J. T. \& Fowler, C. J. (1999). Learning technology and usability: A frame work for understanding courseware. Interacting with Computers, 11(5), 485-497.

Mingers, J. (2004). Real-azing information systems: Critical realis $m$ as underpinning philosophy for information systems. Information and Organization, 14, 87-103

National Research Council. (1999). Being fluent with information technology. Washington, DC: National Academy Press.

Nauer, P. (1992). Computing: A human activity. New York: ACM Press.

Nygård, K. (1986). Program development as a social activity. In H. Kugler (Ed.), Information processing (pp. 189-198). Amsterdam: Elsevier.

Papert, S. (1980). Mindstorms: Children, computers, and powerful ideas. New York: Basic Books.

Piaget, J. (1971). Genetic epistemology. New York: W.W. Norton.

Ratuporo, J., Poentinen, S., \& Kukkonen, J. (2006). Towards the information society - The case of Finnish teacher education. Informatics in Education 2, 285-300.

Schubert, S., \& Schwill, A. (2004). Didactics of informatics [In German. Original title: Didaktik der Informatik]. Berlin: Spektrum Akademischer Verlag.

Schulte, C. (2002). Towards a pedagogical fra mework for teaching programming and object-oriented modelling in secondary education. Proceedings of SECIII 2002, Dortmund, July, 22-26.

Steffe, P. L. \& Gale, J. (1995). Constructivism in education. New Jersey: Lawrence Erlbaum.

Trede, M. (2007). Know your discipline: Teaching the philosophy of computer science. The Journal of Information Technology Education, 6, 105-122. Retrieved September 2, 2008 from http://jite.org/documents/Vol6/JITEv 6p105-122Tedre 266.pdf 
UNESCO. (2002). Information and communication technology in education: A curriculum for schools and programme of teacher development. Retrieved September 17, 2008 from http://unesdoc.unesco.org/images/0012/001295/129538e.pdf

Valcke, M., Rots, I., Verbecke, M. \& Van Brak, J. (2007). ICT teacher training: Evaluation of the curriculu $\mathrm{m}$ and train ing approach in Flanders. Teacher and Teacher Education, 23(6), 795-708.

Vygotsky, L. S. (1978). Mind in society: The development of higher psychological processes. Cambridge, MA: Harvard University Press.

Webb, M. (2002). Pedagogical reasoning: Issues and solutions for the teaching and learning of ICT in secondary schools. Education and Information Technologies, 7(3), 237-255.

Whitaker, R. (2007) Applying phenomenology and hermeneutics in IS design: A report on field experiences. Informing Science: The International Journal of an Emerging Discipline, 10, 63-96. Retrieved fro $\mathrm{m}$ http://inform.nu/Articles/Vol10/DblHelix063-096.pdf

Winograd, T., \& Flores, F. (1987). Understanding, computers and cognition: A new foundation for design. New York: Addison-Wesley.

Woollard, J. (2005). The imp lication of the pedagogic metaphor for teacher education in computing. Technology, Pedagogy and Education, 14(2), 189-204.

Wulf, T. (2005). Constructivist approaches for teaching computer programming. SIGITE'05, October 2022, 2005, Newark, Jew Jersey, USA, 245-248.

\section{Biography}

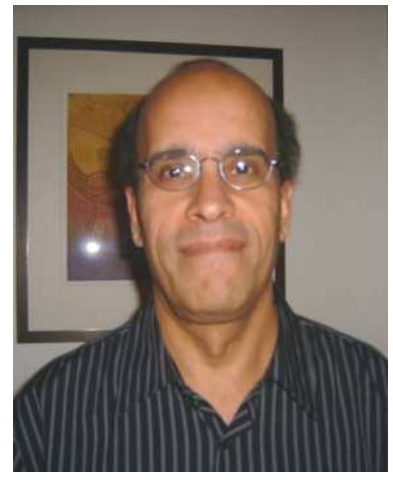

Said Hadje rrouit received the MS and $\mathrm{PhD}$ degrees in Software Engineering and Artificial Intelligence from the Technical University of Berlin (Germany), in 1985 and 1992, respectively. He joined University of Agder, Kristiansand (Norway) in 1991. He is currently an Associate Professor of Informatics and ICT Education at the Faculty of Technology and Science. He has been in the teaching profession for 28 years. He has extensive experience in teaching object-oriented programming, Web engineering, software development, databases, and didactics of ICT. His research interests include Web engineering education, didactics of informatics, ICT and learning, ICT in mathematics education, e-Learning and Web-based learning systems. Hadjerrouit has published over 70 papers in international journals and conference proceedings. 